Bunin, G. R., Tseng, M., Li, Y., Meadows, A. T. and Ganguly, A. (2012), Parental diet and risk of retinoblastoma resulting from new germline RB1 mutation. Environ. Mol. Mutagen., 53: 451-461. doi: 10.1002/em.21705

\title{
Parental Diet and Risk of Retinoblastoma Resulting from New Germline RB1 Mutation
}

Greta R. Bunin, ${ }^{1 *}$ Marilyn Tseng, ${ }^{2}$ Yimei Li, ${ }^{1}$ Anna T. Meadows, ${ }^{1}$ and Arupa Ganguly ${ }^{3}$

${ }^{1}$ Division of Oncology and Center for Childhood Cancer Research, Children’s

Hospital of Philadelphia, Philadelphia, Pennsylvania

${ }^{2}$ Department of Kinesiology, California Polytechnic University, San Luis Obispo,

California

${ }^{3}$ Department of Genetics, University of Pennsylvania, Philadelphia, Pennsylvania

We conducted a case-control study of sporadic bilateral retinoblastoma, which results from a new germline RB1 mutation, to investigate the role of parents’ diet before their child’s conception. Parents of 206 cases from nine North American institutions and 269 controls participated; of these, fathers of 184 cases and 223 controls and mothers of 204 cases and 260 controls answered a food frequency questionnaire administered by phone about their diet in the year before the child's conception. Cases provided DNA for RB1 mutation testing. We assessed parents’ diet by examining 19 food groups. Father's intake of dairy products and fruit was associated with decreased risk and cured meats and sweets with increased risk. Mother's intake was not associated with disease for any food group. Considering analyses adjusted for the other food groups significantly associated with disease, energy intake, and demographic characteristics as well as more fully adjusted models, the associations with father's dairy products and cured meat intake were the most robust. In the fully adjusted, matched analysis, the odds ratios per daily serving were 0.70 (95\% confidence interval (CI) 0.49-1.00, $\mathrm{P}=$ 0.047) for dairy products and 5.05 (CI 1.46-17.51, P = 0.01) for cured meat. The pattern of 
associations with paternal but not maternal diet is consistent with the fact that $85 \%$ of new germline RB1 mutations occur on the father's allele. As few human data exist on the role of diet in any condition resulting from new germ-cell mutation, additional studies will be needed to replicate or refute our findings.

\section{INTRODUCTION}

Children born with a new germline mutation in the RB1 gene have a 95\% chance of developing retinoblastoma, a rare cancer of the embryonal retina. In this situation of unaffected parents and a de novo germline mutation, the disease is referred to as sporadic germline retinoblastoma; the majority of these children have bilateral disease. Sporadic germ-line retinoblastoma accounts for 30\% of retinoblastoma in developed countries [Knudson, 1971] and is diagnosed in an estimated 100 children per year in the US [Knudson, 1971; Ries et al., 1999]. Although the molecular events leading to this and other forms of retinoblastoma are well understood, the role of environmental exposures in these molecular events has largely been ignored. In animals, radiation and over 30 chemicals induce new germline mutations with deleterious effects on the offspring [Russell et al., 1981, 1998; Shelby et al., 1993]. However, studies of exposed human populations, i.e. atomic bomb survivors and cancer patients treated with radiation and mutagenic drugs, have not detected an effect [Bouffler et al., 2006; Committee to Assess Health Risks from Exposure to Low Levels of Ionizing Radiation, 2006]. A consensus has recently emerged that the human germline is not resistant to mutagenic effects of environmental exposures but that limitations of previous research explain the discrepancy between animal and human studies [Elespuru and Sankaranarayanan, 2007; Wyrobek et al., 2007]. These limitations include the small size of study populations relative to the low baseline frequency of individual Mendelian disorders, the study of congenital anomalies as surrogates when only a small fraction result from new germline mutation, and 
the lack of practical ways to associate the time of origin of mutations with exposures [Elespuru and Sankaranarayanan, 2007]. Considering both the animal and human data, DeMarini concluded that ionizing radiation, chemotherapy, smoking, and air pollution can be considered human germ-cell mutagens, if one applies criteria similar to those that the International Agency for Research on Cancer uses to assess carcinogenicity, namely positive animal data in at least two species and/or repeated positive results in one, and in the absence of definitive human epidemiology evidence, human biomarker data strongly relevant to mechanistic data in animals. DeMarini predicts that genomic technology will soon result in the confirmation of these human germ-cell mutagens and the identification of others [Demarini, 2012].

Food contains mutagens that might increase risk of germ-cell mutation based on evidence for their effects in somatic cells. For example, meat, which contains heterocyclic amines formed during cooking, and cured meats, which contain precursors of mutagenic N-nitroso compounds, might increase risk [Ferguson and Philpott, 2008]. Vitamin C and flavonoids might lower risk as they inhibit mutation. In addition to effects hypothesized based on evidence for somatic mutation, protective effects for dietary antioxidants, zinc and folate against germ-cell mutation have been hypothesized based on their roles in spermatogenesis and DNA synthesis and repair. Low folate was associated with aneuploidy in human sperm [Young et al., 2008] and abnormal maternal folate metabolism has been associated with Down syndrome, an aneuploid condition, in some but not all studies [James et al., 1999; O’Leary et al., 2002; Chango et al., 2005; da Silva et al., 2005]. However, aneuploidy arises through different mechanisms than the RB1 gene mutations that lead to retinoblastoma and, to our knowledge, there is no direct evidence that diet influences these mutations. Given the limited data on diet and germ-cell mutation, we choose to investigate diet broadly, by examining food groups. 
The majority, about 85\%, of the new germline mutations that result in retinoblastoma occur on the father's allele [Zhu et al., 1989; Dryja et al., 1997]. The small proportion of mutations of maternal origin might suggest that detection of effects of mothers' exposures will be difficult and that research should only examine the father's exposures. However, because we recently observed associations of sporadic germline retinoblastoma with both mothers' and fathers' exposure to medical radiation before the child's conception [Bunin et al., 2011a], we investigated the diet of both parents. In animals, exposures can induce mutation in stem cell spermatogonia that persist throughout reproductive life as well as in later cell stages of spermatogenesis. Thus, the critical time period for human germ-cell mutation could be the 3 months before conception during which the spermatozoa develop or many years before conception if the stem cells are susceptible. For practical reasons, we studied parents' diet in the year before the child's conception. We report here the results for food groups of both mothers and fathers.

\section{MATERIALS AND METHODS}

Institutional review boards of the institutions that participated in the study (Children's Hospital of Philadelphia, Wills Eye Institute (Philadelphia), Memorial Sloan-Kettering Cancer Center (New York), University of Illinois—Chicago, Children’s Memorial Hospital (Chicago), Children’s Hospital of Los Angeles, St. Jude Children’s Research Hospital (Memphis), Hospital for Sick Children (Toronto), Children’s Hospital and Regional Medical Center (Seattle), and University of Pennsylvania (Philadelphia)) approved the study. Participants gave verbal consent for the telephone interview and written consent for the use of DNA.

Eligible patients were diagnosed with sporadic bilateral retinoblastoma from January 1998 to May 2006 and treated at a participating institution. We recruited controls who were friends or relatives of the case with a birth year within 2 years of the case's birth year and without a history of 
cancer. The study focused on paternal exposures since 85\% of new RB1 mutations occur on the father's allele [Zhu et al., 1989; Dryja et al., 1997] and thus, we wanted a control group in which the case and control fathers were not biologically related. Therefore, when the control child was a relative rather than a friend, we choose families in which the control father was not a biological relative of the case father. This resulted in a control group consisting of both friends and relatives that was homogeneous in terms of the absence of a biological relationship between case and control fathers. We asked the case parents to enumerate friends and relatives with children from whom we chose those who fit the criteria. For each case, we attempted to recruit one to two friends and one relative.

To be eligible, cases and controls had to reside in North America, have at least one parent who spoke English or Spanish, and have at least one biological parent available for participation, i.e., not be adopted or in foster care.

We conducted telephone interviews with one or both parents of cases and controls to obtain information on diet, vitamin and mineral supplements, medical radiation, occupation, and smoking. The analysis of occupational exposures is not yet complete and, thus, occupation is not considered in this report. We modified the Willett food frequency questionnaire (FFQ) [Willett, 1998a] for use in a telephone interview for the year before the child's conception and by adding a small number of foods to aid in the estimation of zinc and vitamin C intake, two nutrients with roles in spermatogenesis. The final FFQ had 71 food items and 20 supplement items and did not ask about portion size. For fruits, the FFQ estimated average intake over 1 year based on responses on frequency of fruit consumption when in season and frequency during the remainder of the year. (The relevant questionnaire sections are provided as online supplements.) Trained interviewers from Children’s Hospital of Philadelphia conducted the interviews from 2002 to 2007; it was not 
practical to blind them to case-control status. Two individuals conducted $80 \%$ of the interviews. Parents who were not able or willing to complete the full interview were offered a shortened version of the questionnaire that did not include the FFQ.

Mutation Detection

RB1 mutation analysis was performed for 190 of the cases as described previously [Richter et al., 2003; Nichols, 2005]. All 27 exons of RB1, including the flanking intronic regions, were sequenced by the polymerase chain reaction (PCR) method using DNA isolated from peripheral blood lymphocytes. When a missense mutation was identified that was novel, i.e., not previously reported in retinoblastoma, a set of 50 control DNA samples were examined for the same alteration to determine whether it was a polymorphism or a disease-causing mutation. Large deletions and rearrangements were detected by quantitative-real time PCR assays designed for each individual exon of RB1, including the promoter and 3' untranslated regions. All observed mutations were confirmed by repeat analysis using an independently isolated sample of DNA.

When a RB1 mutation was found, we screened the child's parents for the same mutation; 359 parents provided DNA for this purpose. When a parent carried the mutation found in the child, the child had familial retinoblastoma and was ineligible for the study. Of cases with complete sets of samples, $6.5 \%$ were found to have familial retinoblastoma or were mosaic for the mutation. Therefore, of the 37 cases without complete sets of samples, we estimate that 2 (6.5\%) did not have a new germline RB1 mutation. We included these 37 cases in our study because of the low level of misclassification.

Mutations were categorized as transitions (substitution of a purine for the other purine or a pyrimidine for the other pyrimidine) at CpG sites; other transitions, i.e. at non-CpG sites; 
transversions (substitution of a purine for a pyrimidine or pyrimidine for a purine); frameshifts (insertions or deletions of $<100$ base pairs), and large deletions/rearrangements.

Statistical Analysis

We compared demographic and other characteristics of cases and controls using $\mathrm{v}^{2}$ tests for categorical variables and t-tests for continuous variables. Pearson correlations between pairs of food groups were calculated. The mutation type and base change of the disease-causing mutation in RB1 were compared between extreme quartiles of selected food groups. As the numbers in some cells were small, we calculated exact P's for v $v^{2}$ test using Monte Carlo simulations [Agresti, 1992].

We assessed the association between diet and risk of retinoblastoma in two ways. We conducted analyses restricted to the matched case-control sets (“Case-control sets”) using conditional logistic regression. This analytic approach accounts for the nonindependence of cases and controls in the matching factor and, in this study, in other factors that are shared among friends/relatives; it is the epidemiologically rigorous way to analyze the data given the matched design. However, since a substantial proportion of cases did not have controls, we also compared all cases and all controls (“Complete population”) using logistic regression as the most inclusive analysis.

For 19 food groups, the total number of servings per day was calculated by summing the number of servings per day of the constitutive foods. The food groups and the number of items included in each were: fruit (6), citrus fruit (2), dairy (7), vegetables excluding potatoes (14), cruciferous vegetables (2), green leafy vegetables (2), yellow vegetables (4), tomatoes and tomato sauce (2), legumes (3), meat and seafood (14), poultry (2), fresh red meat (4), cured meat 
(3), seafood (5), shellfish (3), other fish (2), grains (8), fats (4), sweets including beverages (9), fried food (4), and alcohol (3). (The appendix lists the food items in each food group.)

We analyzed intake of individual food groups as continuous variables. We also performed analyses by quartile of intake, which provided similar results and are not presented here. Individual food groups were analyzed for mothers and fathers separately and adjusted for a minimal set of other variables, namely child's birth year (the matching factor) and the possible confounders of race/ethnicity (non-Hispanic white, other), education level (not a college graduate, college graduate), and energy intake (total calories). The food groups that were significantly associated with disease were then analyzed further by including all those food groups in a single model. For these analyses, we present a minimally adjusted model that includes father's race/ethnicity, father's educational level, child's birth year, and father's energy intake, as well as a "fully adjusted"model that includes all the significant food groups, the covariates in the minimally adjusted model, and additional covariates selected by stepwise procedure from among the following: mother's educational level, father's smoking (nonsmoker, 1-10 cigarettes/day, >11 cigarettes/ day), mother's smoking (nonsmoker, 1-10 cigarettes/day, >11 cigarettes/ day), mother's use of the following supplements in the year before conception: multivitamin, vitamin C; father's use of the following supplements in the year before conception: multivitamin, vitamin C, vitamin E, calcium; father's dose of gonadal medical radiation before the child's conception (0, 1-49 mGy, >50mGy), mother's dose of gonadal medical radiation before the child's conception (0, 1-24 mGy, > 25 mGy). We performed analyses to assess interaction between selected food groups by including a multiplicative interaction term in the model.

STATA/IC version 10.0 was used to perform conditional logistic regression and SPSS version 16.0 for unconditional logistic regression of food groups considered one at a time. The 
simultaneous analyses of multiple food groups (minimally adjusted model and fully adjusted model using stepwise selection) and the calculation of exact P's for contingency tables were performed using SAS version 9.2. Statistical significance was defined as two-sided $\mathrm{P}<0.05$.

\section{RESULTS}

Recruitment and Characteristics of Cases and Controls

Participating institutions identified 236 patients. Patients were excluded for the following reasons: biological parent not available due to foster care or adoption $(n=2)$, neither parent spoke English or Spanish $(n=5)$, inability to locate $(n=1)$, physician requested no contact $(n=$

2), parents refused $(n=9)$, mutation testing showed an inherited RB1 mutation or mosaicism (n $=11)$. The mother $(n=204)$ and/or father $(n=203)$ of the remaining 206 patients were interviewed for the study.

The details of the control recruitment have been published previously [Bunin et al., 2011b] and will be summarized briefly here. Although we aimed to recruit one relative and one to two friend controls per case, some families were unable or unwilling to nominate any controls. The other case families each nominated one to three friends and relatives for a total of 374 potential controls. Of the 374 potential control children, mothers of 263 (70\%) and fathers of 247 (66\%) completed interviews. The majority of controls who were not interviewed actively or passively refused; 12 control children were ineligible. We recruited at least one control parent for 146 (71\%) of the 206 case families.

Of the 203 case fathers, 19 did not provide information on diet because they completed the shorter questionnaire, 55 had no interviewed control, and 7 had one or more controls but none with diet information. Of the 247 interviewed control fathers, 17 did not provide diet information and 7 were controls of cases without diet information. Two additional case fathers who did 
not have controls were excluded from the complete population because of improbable energy intake ( $>6,000$ or $<500 \mathrm{kcal} /$ day). Thus, for the diet analysis, 182 case fathers and 223 control fathers formed the "complete population” and 122 case fathers and 223 control fathers formed 122 matched case-control sets. All 204 interviewed case mothers provided diet information but 2 had improbable energy intake, 60 did not have any controls, and 2 did not have a control with diet information. All but 3 of the 263 control mothers provided diet information, resulting in 140 case and 260 control mothers who formed 140 matched sets. The complete population consists of 202 case and 260 control mothers. For a small proportion of participants, the other parent provided the information (Table I).

Case and control children were similar in birth year, the matching factor. Control parents were more likely to be non-Hispanic white, have at least a college education, have a higher income, be married, and be a nonsmoker compared with cases. When only the case-control sets were considered, case parents and control parents were similar in race/ethnicity, marital status, age at the index child's birth, and income (Table I), but they differed in father's educational level and mother's smoking.

\section{Food Groups}

In analyses of the complete population and of the matched sets, father's intake of dairy products was significantly inversely associated with retinoblastoma in his child (Table II). Father's intake of the general group of meat and seafood and of the subgroup cured meats (bacon, hot dogs, and processed meats) showed significantly increased ORs in the complete and matched analyses, with larger ORs and smaller P's for cured meats. The elevated OR for meat and seafood overall appeared to reflect the larger OR for cured meats and thus, we did not further consider the main category. Father's fruit intake was associated with decreased risk, which was 
significant for only the matched analysis. For sweets, a significantly increased OR was observed in only the matched analysis. The OR for seafood was nonsignificantly elevated and appeared to result from an increased and imprecise OR for shellfish (data not shown). For the remaining food groups including subgroups of fruits and vegetables, no noteworthy ORs were observed (data not shown for the fruit and vegetable subgroups).

Among the food groups with elevated ORs, dairy and fruit were significantly correlated $(\mathrm{r}=$ $0.21, \mathrm{P}<0.001)$, as were cured meats and sweets $(\mathrm{r}=0.24, \mathrm{P}<0.001)$. Dairy was only weakly correlated with cured meats and sweets $(r=0.10, \mathrm{P}=0.05$ for both $)$.

Mother's intake was not significantly associated with disease for any of the food groups including the fruit and vegetable subgroups (Table III). Most of the ORs were close to 1.0. For cured meats, the ORs were somewhat, but not significantly, increased.

To further explore the observed associations, we simultaneously analyzed the food groups that were statistically significant in the complete population and/or the matched analysis, namely father's dairy, fruit, cured meat, and sweets intake (Table IV). In the minimally adjusted models, the associations with father's dairy, cured meat, and sweets intake remained similar in magnitude and significance to the analyses of single food groups. However, the association with fruit was attenuated and no longer statistically significant. In the fully adjusted models, the association with dairy intake was significant in both the complete population and matched sets analyses, with ORs of 0.7 to 0.8 . Cured meats and sweets were significant in the matched sets analyses only, and fruit was not significant in either analysis. There was no evidence of interaction between cured meats and either fruit or citrus fruit intake.

We explored the possibility of interaction of food groups with paternal smoking and age, two factors associated with germline mutation. Associations with cured meat and dairy occurred in 
nonsmokers but not among the small group of smokers (58 cases, 45 controls). In fathers above the median age of our study population, the associations with cured meat and dairy were stronger than in the younger fathers. The interaction terms of smoking and paternal age with each of the two food groups were not statistically significant.

RB1 Mutation

Mutation type and base change did not differ significantly between cases in the lowest and highest quartiles of intake of dairy, cured meat, fruit, and sweets (Tables V and VI). Two nonsignificant differences were noted. The proportion of transversions varied by level of sweets intake. In the groups associated with high risk, i.e. high cured meat, low dairy, low fruit, and high sweets intake, there was an excess of $G$ to A mutations; the difference was largest between low and high dairy intake (Table VI).

\section{DISCUSSION}

We observed an association of the father's more frequent consumption of dairy and fruit with lower risk of sporadic bilateral retinoblastoma in his child. Father's more frequent consumption of cured meat and sweets was associated with increased risk. The findings for dairy and cured meats are the most compelling because the associations showed more consistent statistical significance in analyses that adjusted for confounders and in both the complete population and the matched sets. Mother's diet as assessed by food groups was not significantly associated with risk. [Table 1] [Table 2] [Table 3] [Table 4] [Table 5] [Table 6] 
Consumption of dairy food by the father appeared to decrease risk. The association was consistent in magnitude across analyses of the complete population and matched sets, of single and multiple food groups, and in minimally and fully adjusted models. It was statistically significant in all analyses except one (Table IV). Despite the robustness of the observation, a mechanism is not obvious. Individuals with high intake of dairy foods have a reduced risk of colorectal cancer, which may reflect effects of calcium and/or vitamin D [Pufulete, 2008]. Calcium and vitamin D may act against colorectal cancer by inhibiting cell proliferation, sequestering bile acids, and regulating growth factors and cytokines, mechanisms which do not seem relevant to retinoblastoma resulting from a new germline mutation [Pufulete, 2008]. Other components of dairy foods have been studied to a lesser extent. Based on evidence from cell culture and animal experiments, a recent review concluded that whey protein, a heterogeneous group of proteins that comprises about $20 \%$ of the protein in milk, has the potential to reduce the risk of cancer [Parodi, 2007]. Whey's anticancer effect has been observed mostly for colon and breast tumors in animals and may result from its ability to increase synthesis of glutathione. Glutathione acts in several ways that could potentially reduce mutation. For example, it participates in the destruction of reactive oxygen species, the detoxification of some carcinogens, and the maintenance of ascorbic acid in its reduced, antioxidant state. Thus, although the inverse association we observed with father's intake of dairy foods needs replication, some data support its biologic plausibility.

The other compelling finding was the association of father's intake of cured meats with increased risk in the single food group analyses and the multiple food group analyses, except for the fully adjusted model in the complete population. The ORs were much higher in the matched analyses with ORs of about 5 compared with the unmatched ORs of about 2. The matched 
analyses might reflect better adjustment of confounders or enhanced random variation due to smaller numbers.

The association with cured meat has biologic plausibility. Cured meats are processed with sodium nitrite, which can combine with amines and amides to form N-nitroso compounds (NOCs) [Lijinsky, 1992]. Cured meats can also contain already formed NOCs [Lijinsky, 1992], many of which are potent mutagens in animals, including in germ cells. In fact, researchers use one NOC, N-ethyl-Nnitrosourea, to induce germ-cell mutations in male mice, leading to its distinction as the "supermutagen"of the mouse germline [Probst and Justice, 2010]. Vitamin C inhibits NOC formation from precursors [National Academy of Sciences, 1981], but we did not observe an effect of citrus fruit, which is rich in vitamin C, nor did we observe an interaction between fruit or citrus fruit and cured meats. It has been suggested that vitamin $\mathrm{C}$ and the cured meats have to be eaten together for the protective effect, and our study did not collect the information necessary to assess this.

If paternal diet affects risk of germline mutation, it would be important to know if it acts additively or synergistically with other mutagens. Although our study was not designed to address this question, we explored the possibility of interaction of diet with paternal age and smoking. The effects of cured meats and dairy were limited to nonsmokers, but the number of smokers was small and the interaction was not statistically significant, indicating the difference between smokers and nonsmokers is likely to have occurred by chance. Older fathers have an increased risk of having a child with a de novo mutation for some genetic conditions, but for retinoblastoma, the paternal age effect is likely small or nonexistent [Moll et al., 1996]. Nonetheless, we explored the question of interaction. The effects of dairy and cured meats appeared to be stronger among older compared with younger fathers, but the interaction was not 
significant. The possibility of interactions among possible germ-cell mutagens should be explored further.

Although a significant inverse relationship with paternal fruit consumption was observed in the matched analysis of single food groups, fruit was not statistically significant in any of the multiple food group analyses. We might have expected to observe an inverse association with fruit, as these foods contains vitamin C and other antioxidants which can inhibit mutagenesis in vivo and in vitro [Gaziev et al., 1995; Duthie et al., 1996; Odin, 1997]. In addition, seminal fluid contains concentrations of vitamin C six times higher than those in blood, and oxidative damage was observed to increase when vitamin C in seminal fluid was depleted by a controlled diet [Fraga et al., 1991]. Based on these observations, vitamin C has been hypothesized to protect sperm against oxidative DNA damage [Woodall and Ames, 1997]. However, our data do not support this hypothesis, as we did not see a convincing association with fruit or with the subgroup of citrus fruit, which is particularly high in vitamin C.

Father's intake of sweets was associated with increased risk, but only in analyses of the matched sets. As the analyses of matched sets are the most epidemiologically rigorous, these results are consistent with an effect of sweets. Sweets are high in both sugar and fat and promote weight gain and obesity. Obesity is associated with several types of cancer and may act through hyperinsulinemia, inflammation, or other mechanisms. More relevant to sporadic germline retinoblastoma, obesity in male mice was observed to exacerbate the effect of an environmental toxicant on germline mutation [Ghanayem, 2010]. Although there is evidence linking high sugar and fat intake to obesity and obesity to cancer and germline mutation, our data are not consistent with an effect of obesity on risk of retinoblastoma as case and control Environmental and 
Molecular Mutagenesis. fathers did not differ in body mass index. The association with sweet intake among fathers was inconsistent across analyses and may have been a chance finding. The mutation spectra did not differ dramatically by father's level of intake of the food groups associated with risk. G to A transitions were somewhat more common in the higher risk groups, with a generally larger difference for the food groups with the more robust findings, namely dairy and cured meats. The differences were based on very small numbers and were not statistically significant. A strong correlation between mutation spectrum and exposure would have made our findings more convincing. In geographic areas with high aflatoxin exposure, about $45 \%$ of liver cancers have the signature mutation compared with $1 \%$ in low aflatoxin areas [Smela et al., 2001; Pfeifer et al., 2002]. Clearly, we did not observe this level of specificity with diet. In lung cancers of smokers, about 30\% have a $\mathrm{G}$ to $\mathrm{T}$ transversion in p53 compared with 12\% in nonsmokers [Pfeifer et al., 2002; Smela et al., 2001]. The specificity we observed for dairy and cured meats is similar but based on such small numbers that we can draw no conclusions. The study of additional families will help clarify our findings.

Overall, our results suggest a role for paternal diet but not maternal diet in the etiology of new germline mutations in the RB1 gene. The effect of paternal but not maternal diet on risk is consistent with the fact that $85 \%$ of new germline RB1 mutations occur on the father's allele [Zhu et al., 1989; Dryja et al., 1997]. Our findings are consistent with an effect at any stage of spermatogenesis. We studied diet in the year before the child's conception, a time period that encompasses the complete process of spermatogenesis, which is about 3 months long [Clermont, 1972]. In animals, radiation and chemicals induce germline mutations at all stages of spermatogenesis, including stem cell spermatogonia, which persist throughout reproductive life [Russell, 1994]. As adult diet is fairly stable, our findings do not rule out an effect beyond the 1 
year interval that we studied. The stability of adult diet also implies that observational studies are unlikely to pinpoint a critical time period.

The major strength of our study was our ability to limit it to cases resulting from one mechanism, namely new germline mutation. Nearly all patients with an inherited mutation could be excluded by mutation testing of the child followed by screening of the parents for the same mutation. Although smaller than most cancer epidemiology studies, our study is large for a study of sporadic germline retinoblastoma or of another condition caused by new germline mutation, and we do not know of a larger one.

Our study also has weaknesses. Its case-control design mandated assessment of diet in the past. Parents reported their diet a median of 4.5 years in the past, with a range of 1 to 15 years. Adult diet is reasonably well reported up to 10 years in the past, but not as well as current diet [Willett, 1998b]. In the best of circumstances, the assessment of diet using a FFQ is subject to substantial measurement error [Kristal et al., 2005]. Nondifferential measurement error generally reduces the power to detect associations and, thus, we may have missed some associations. As in many case-control studies, recall, interviewer, and selection bias might also have affected our results. If parents of cases recalled their diet differently compared with parents of controls, recall bias may have affected our results in ways that either produced spurious findings or masked true associations. The interviewers were not blinded to whether subjects were cases or controls, and this knowledge may have affected how they administered the questionnaire. Selection bias resulting in a nonrepresentative case or control group may also have affected our study results, since our study was hospital based, not population based. Further, the unintentional close matching of cases and their friend/relative controls on socioeconomic status and parental age may also have produced bias that masked a true association. It is also possible that parents chose more 
health-conscious friends and relatives to nominate as controls or that more health conscious individuals chose to participate as controls, which could produce protective associations with components of a healthy diet. However, the observed findings were for specific food groups rather than for multiple categories of healthy and unhealthy foods. For example, we observed associations with fruit but not vegetables, for dairy products but not fish, and for cured meats but not red meats overall. If selection bias among controls or recall or interviewer bias explained the results, we might have expected to see associations for related food categories, such as both fresh red meat and cured meat, and both fruit and vegetables. Finally, we performed many statistical tests and some results may have occurred by chance alone.

In conclusion, we observed associations between father's diet before his child's conception and risk of retinoblastoma in his child that results from a new germline mutation. These results fit the molecular data that most of these mutations have a paternal origin. We know of no other study of diet in relation to retinoblastoma or other conditions that result from new germ-cell mutation. Therefore, additional studies will be needed to replicate or refute our findings. Our results suggest that studies of conditions that result from new germ-cell mutation may elucidate modifiable dietary risk factors.

\section{ACKNOWLEDGMENTS}

The authors thank the families of the patients and their relatives and friends for their participation. The authors also thank Drs. Debra Friedman, Carol Shields, Kim Nichols, Ann Leahey, Ira Dunkel, Rima Jubran, Carlos Rodriguez-Galindo, Mary Lou Schmidt, Joanna WeinEnvironmental and Molecular Mutagenesis. DOI 10.1002/emstein, Stewart Goldman, David Abramson, Matthew Wilson, Brenda Gallie, Helen Chan, and Michael Shapiro for enrolling and caring for the patients and Drs. Avital Cnaan and Larry Kushi for their assistance in the design of 
the study. The authors thank the clinical research staff at the participating centers and study staff at Children’s Hospital of Philadelphia for their diligent efforts particularly Bethany Barone, Jaclyn Bosco, Greta Anschuetz, Sheila Kearney, and the late Jean Rodwell.

\section{REFERENCES}

Agresti A. 1992. A survey of exact inference for contingency tables. Stat Sci 7:131-153.

Bouffler SD, Bridges BA, Cooper DN, Dubrova Y, McMillan TJ, Thacker J, Wright EG, Waters R. 2006. Assessing radiation-associated mutational risk to the germline: repetitive DNA sequences as mutational targets and biomarkers. Radiat Res 165:249-268.

Bunin GR, Felice MA, Davidson W, Friedman DL, Shields CL, Maidment A, O’Shea M, Nichols KE, Leahey A, Dunkel IJ, Jubran R, Rodriguez-Galindo C, Schmidt M, Weinstein JL, Goldman S, Abramson DH, Wilson MW, Gallie BL, Chan HSL, Shapiro M, Cnaan A, Ganguly A, Meadows AT. 2011a. Medical radiation exposure and risk of retinoblastoma resulting from new germline RB1 mutation. Int J Cancer 128:2393-2404.

Bunin GR, Vardhanabhuti S, Lin A, Anschuetz GL, Mitra N. 2011b. Practical and analytical aspects of using friend controls in case-control studies: Experience from a case-control study of childhood cancer. Paediatr Perinat Epidemiol 25:402-412.

Chango A, Fillon-Emery N, Mircher C, Blehaut H, Lambert D, Herbeth B, James SJ, Rethore MO, Nicolas JP. 2005. No association between common polymorphisms in genes of folate and homocysteine metabolism and the risk of Down’s syndrome among French mothers. Br J Nutr 94:166-169.

Clermont Y. 1972. Kinetics of spermatogenesis in mammals: Seminiferous epithelium cycle and spermatogonial renewal. Physiol Rev 52:198-236. 
Committee to Assess Health Risks from Exposure to Low Levels of Ionizing Radiation. 2006. Heritable genetic effects of radiation in human populations. Health risks from exposure to low levels of ionizing radiation: BEIR VII Phase 2, Board on Radiation Effects Research, National Research Council. Washington, DC: National Academies Press.

da Silva LR, Vergani N, Galdieri Lde C, Ribeiro Porto MP, Longhitano SB, Brunoni D, D’Almeida V, Alvarez Perez AB. 2005. Relationship between polymorphisms in genes involved in homocysteine metabolism and maternal risk for Down syndrome in Brazil. Am J Med Genet A 135:263-267.

Demarini DM. 2012. Declaring the existence of human germ-cell mutagens. Environ Mol Mutagen 53:166-172.

Dryja TP, Morrow JF, Rapaport JM. 1997. Quantification of the paternal allele bias for new germline mutations in the retinoblastoma gene. Hum Genet 100:446-449.

Duthie SJ, Ma A, Ross MA, Collins AR. 1996. Antioxidant supplementation decreases oxidative DNA damage in human lymphocytes. Cancer Res 56:1291-1295.

Elespuru RK, Sankaranarayanan K. 2007. New approaches to assessing the effects of mutagenic agents on the integrity of the human genome. Mutat Res 616:83-89.

Ferguson LR, Philpott M. 2008. Nutrition and mutagenesis. Annu Rev Nutr 28:313-329.

Fraga CG, Motchnik PA, Shigenaga MK, Helbock HJ, Jacob RA, Ames BN. 1991. Ascorbic acid protects against endogenous oxidative DNA damage in human sperm. Proc Natl Acad Sci USA 88:11003-11006.

Gaziev AI, Podlutsky AJ, Panfilow BM, Bradbury R. 1995. Dietary supplements of antioxidants reduce hprt mutant frequency in splenocytes of aging mice. Mutat Res 338:77-86. 
Ghanayem BI, Bai R, Kissling GE, Travlos G, Hoffler U. 2010. Diet-induced obesity in male mice is associated with reduced fertility and potentiation of acrylamide-induced reproductive toxicity. Biol Reprod 82:96-104.

James SJ, Pogribna M, Pogribny IP, Melnyk S, Hine RJ, Gibson JB, Yi P, Tafoya DL, Swenson DH, Wilson VL, Gaylor DW. 1999. Abnormal folate metabolism and mutation in the methylenetetrahydrofolate reductase gene may be maternal risk factors for Down syndrome. Am J Clin Nutr 70:495-501.

Knudson AG. 1971. Mutation and cancer: statistical study of retinoblastoma. Proc Natl Acad Sci USA 68:820-823.

Kristal AR, Peters U, Potter JD. 2005. Is it time to abandon the food frequency questionnaire? Cancer Epidemiol Biomarkers Prev 14:2826-2828.

Lijinsky W. 1992. Chemistry and biology of N-nitroso compounds. New York, New York: Cambridge University Press.

Moll AC, Imhof SM, Kuik J, Bouter LM, Den Otter W, Bezemer PD, Koten JW, Tan KEWP. 1996. High parental age is associated with sporadic hereditary retinoblastoma: The Dutch Retinoblastoma Register 1862-1994. Hum Genet 98:109-112.

National Academy of Sciences. 1981. The health effects of nitrate, nitrite and N-nitroso compounds. Washington, D.C.:National Academy Press.

Nichols KE HM, Godmilow L, Bunin G, Shields C, Meadows A, Ganguly A. 2005. Sensitive multi-step clinical molecular screening of 180 unrelated individuals with retinoblastoma detects 36 novel mutations in the RB1 gene. Hum Mutat 25:566-574. 
O’Leary VB, Parle-McDermott A, Molloy AM, Kirke PN, Johnson Z, Conley M, Scott JM, Mills JL. 2002. MTRR and MTHFR polymorphism: Link to Down syndrome? Am J Med Genet 107:151-155.

Odin AP. 1997. Vitamins as antimutagens: Advantages and some possible mechanisms of antimutagenic action. Mutat Res 386:39-67. Parodi PW. 2007. A role for milk proteins and their peptides in cancer prevention. Curr Pharm Des 13:813-828.

Pfeifer GP, Denissenko MF, Olivier M, Tretyakova N, Hecht SS, Hainaut P. 2002. Tobacco smoke carcinogens, DNA damage and p53 mutations in smoking-associated cancers. Oncogene 21:7435- 7451.

Probst FJ, Justice MJ. 2010. Mouse mutagenesis with the chemical supermutagen ENU. Methods Enzymol 477:297-312.

Pufulete M. 2008. Intake of dairy products and risk of colorectal neoplasia. Nutr Res Rev 21:5667.

Richter S, Vandezande K, Chen N, Zhang K, Sutherland J, Anderson J, Han L, Panton R, Branco P, Gallie B. 2003. Sensitive and efficient detection of RB1 gene mutations enhances care for families with retinoblastoma. Am J Hum Genet 72:253-269.

Ries LAG,Smith MA,Gurney JG,Linet M,Tamra T,Young JL,Bunin GR, editors. 1999. Cancer Incidence and Survival Among Children and Adolescents: United States SEER Program 1975-1995. Bethesda, MD:National Cancer Institute.

Russell LB. 1994. Role of mouse germ-cell mutagenesis in understanding genetic risk and in generating mutations that are prime tools for studies in modern biology. Environ Mol Mutagen S24:23-29. 
Russell LB, Selby PB, von Halle E, Sheridan W, Valcovic L. 1981. The mouse specific-locus test with agents other than radiations: Interpretation of data and recommendations for future work. Mutat Res 86:329-354.

Russell WL, Bangham JW, Russell LB. 1998. Differential response of mouse male germ-cell stages to radiation-induced specific-locus and dominant mutations. Genetics 148:15671578.

Shelby MD, Bishop JB, Mason JM, Tindall KR. 1993. Fertility, reproduction, and genetic disease: Studies on the mutagenic effects of environmental agents on mammalian germ cells. Environ Health Perspect 100:283-291.

Smela ME, Currier SS, Bailey EA, Essigmann JM. 2001. The chemistry and biology of aflatoxin B(1): From mutational spectrometry to carcinogenesis. Carcinogenesis 22:535-545.

Willett W. 1998a. Food frequency methods. In: Willett W, editor. Nutritional Epidemiology, 2nd ed. New York: Oxford University Press. pp 74-100.

Willett WC. 1998b. Recall of remote diet. Nutritional Epidemiology, 2nd ed. New York, NY: Oxford University Press. pp 148-156.

Woodall AA, Ames BN. 1997. Nutritional prevention of DNA damage to sperm and consequent risk reduction in birth defects and cancer in offspring. In: Bendich A, Deckelbaum RJ, editors. Preventive Nutrition. The Comprehensive Guide for Health Professionals. Totowa, NJ: Humana Press. pp 373-385.

Wyrobek AJ, Mulvihill JJ, Wassom JS, Malling HV, Shelby MD, Lewis SE, Witt KL, Preston RJ, Perreault SD, Allen JW, Demarini DM, Woychik RP, Bishop JB. 2007. Assessing human germ-cell mutagenesis in the Postgenome Era: A celebration of the legacy of William Lawson (Bill) Russell. Environ Mol Mutagen 48:71-95. 
Young SS, Eskenazi B, Marchetti FM, Block G, Wyrobek AJ. 2008. The association of folate, zinc and antioxidant intake with sperm aneuploidy in healthy non-smoking men. Hum Reprod 23:1014-1022.

Zhu XP, Dunn J, Phillips R, Goddard A, Paton K, Becker A, Gallie B. 1989. Preferential germline mutation of the paternal allele in retinoblastoma. Nature 340:312-313.

\section{APPENDIX: FOOD GROUPS AND THEIR CONSTITUTIVE FOOD ITEMS}

- Fruit: fresh apples or pears; orange juice or grapefruit juice; oranges; peach, apricots, nectarines or plums; bananas; other fruits.

- Citrus fruit: orange juice or grapefruit juice; oranges.

- Dairy: skim or low fat milk; whole milk; yogurt; frozen yogurt or light ice cream; ice cream; cottage or ricotta cheese; other cheese.

- Vegetables excluding potatoes: string beans; broccoli; cabbage; cauliflower or Brussels sprouts; raw carrots; cooked carrots; corn; peas or lima beans; yams or sweet potatoes; spinach, collard or other greens; beans; winter squash; green salad; tomatoes or tomato juice; tomato sauce.

- Cruciferous vegetables: broccoli; cabbage; cauliflower; or Brussels sprouts.

- Green leafy vegetables: spinach, collard or other greens; green salad.

- Yellow vegetables: raw carrots; cooked carrots; yams or sweet potatoes; winter squash.

- Tomatoes and tomato sauce: tomatoes or tomato juice; tomato sauce.

- Legumes: string beans; peas or lima beans; beans.

- Meat and seafood: fried chicken or turkey; chicken or turkey, not fried; bacon; hot dogs; processed meats; liver; hamburger; beef, pork, or lamb as a sandwich or as part of a dish; beef, 
pork, or lamb as a main dish; oysters; fried shellfish; shellfish, not fried; fried fish, other than shellfish; fish other than shellfish, not fried.

- Poultry: fried chicken or turkey; chicken or turkey, not fried.

- Fresh red meat: liver; hamburger; beef, pork, or lamb as a sandwich or as part of a dish; beef, pork, or lamb as a main dish.

- Cured meat: bacon; hot dogs; processed meats.

- Seafood: oysters; fried shellfish; shellfish, not fried; fried fish, other than shellfish; fish other than shellfish, not fried.

- Shellfish: oysters; fried shellfish; shellfish, not fried.

- Other fish: fried fish, other than shellfish; fish other than shellfish, not fried.

- Grains: homemade pie; ready made pie; cake, sweet rolls or other pastry; cookies; white bread, bagels or rolls; dark or whole wheat bread; rice or pasta; cold breakfast cereal.

- Fats: butter, margarine, salad dressing, mayonnaise.

- Sweets including beverages: chocolate; candy without chocolate; homemade pie; ready made pie; cake, sweet rolls or other pastry; cookies; regular soda or pop; fruit drinks with vitamin C added; other fruit drinks.

- Fried foods: fried chicken or turkey; fried shellfish; fried fish, other than shellfish; French fries. Alcohol: beer, wine, liquor. 
Fathers ${ }^{\mathrm{a}}$

\begin{tabular}{|c|c|c|c|c|c|c|}
\hline & & \\
\hline & $\begin{array}{c}\text { All cases } \\
(\mathrm{n}=182) \\
\#(\%)\end{array}$ & $\begin{array}{c}\text { Cases in case-control } \\
\text { sets }(\mathrm{n}=122) \\
\#(\%)\end{array}$ & $\begin{array}{c}\text { Controls } \\
(\mathrm{n}=223) \\
\#(\%)\end{array}$ & $\begin{array}{c}\text { All cases } \\
(\mathrm{n}=202) \\
\#(\%)\end{array}$ & $\begin{array}{c}\text { Cases in case-control } \\
\text { sets }(\mathrm{n}=140) \\
\#(\%)\end{array}$ & $\begin{array}{c}\text { Controls } \\
(\mathrm{n}=260) \\
\#(\%)\end{array}$ \\
\hline \multicolumn{7}{|l|}{ Race/ethnicity ${ }^{\mathrm{a}, \mathrm{b}}$} \\
\hline $\begin{array}{l}\text { Non-Hispanic } \\
\text { White }\end{array}$ & $125(68)$ & $100(82)$ & $192(86)$ & $131(65)$ & $104(74)$ & $208(80)$ \\
\hline Non-Hispanic & $18(10)$ & $6(5)$ & $7(3)$ & $28(14)$ & $16(11)$ & $21(8)$ \\
\hline African American & & & & & & \\
\hline Hispanic & $23(13)$ & $10(8)$ & $16(7)$ & $30(15)$ & $14(10)$ & $22(8)$ \\
\hline Other & $16(9)$ & $6(5)$ & $8(4)$ & $13(6)$ & $6(4)$ & $9(3)$ \\
\hline \multicolumn{7}{|l|}{ Educational level ${ }^{\mathrm{a}, \mathrm{b}}$} \\
\hline No college degree & $107(59)$ & $64(52)$ & $88(39)$ & $120(59)$ & $70(50)$ & $108(42)$ \\
\hline College degree or higher & $75(41)$ & $58(48)$ & $135(61)$ & $82(41)$ & $70(50)$ & $152(58)$ \\
\hline \multicolumn{7}{|l|}{ Annual income ${ }^{c}$} \\
\hline$<\$ 25,000$ & $22(13)$ & $6(5)$ & $15(8)$ & $34(21)$ & $15(13)$ & $31(14)$ \\
\hline$\$ 25-35,000$ & $21(13)$ & $12(11)$ & $15(8)$ & $19(12)$ & $13(11)$ & $18(8)$ \\
\hline$\$ 35-50,000$ & $32(19)$ & $24(21)$ & $33(17)$ & $31(20)$ & $24(21)$ & $48(21)$ \\
\hline$\$ 50-75,000$ & $39(23)$ & $25(22)$ & $49(25)$ & $35(21)$ & $26(23)$ & $46(20)$ \\
\hline$>\$ 75,000$ & $54(32)$ & $46(41)$ & $85(43)$ & $43(26)$ & $37(32)$ & $85(37)$ \\
\hline \multicolumn{7}{|l|}{ Marital status at interview $w^{a, b}$} \\
\hline Married & $167(92)$ & $117(96)$ & $216(97)$ & $162(80)$ & $122(87)$ & $239(92)$ \\
\hline Not married & $15(8)$ & $5(4)$ & $7(3)$ & $40(20)$ & $18(13)$ & $21(8)$ \\
\hline \multicolumn{7}{|l|}{ Age at birth of child } \\
\hline$<20$ & $0(0)$ & $0(0)$ & $0(0)$ & $6(3)$ & $3(2)$ & $8(3)$ \\
\hline $20-24$ & $12(7)$ & $3(2)$ & $11(5)$ & $25(12)$ & $14(10)$ & $29(11)$ \\
\hline $25-29$ & $45(24)$ & $28(23)$ & $62(28)$ & $63(31)$ & $41(29)$ & $77(30)$ \\
\hline $30-34$ & $56(30)$ & $42(34)$ & $76(34)$ & $63(31)$ & $50(36)$ & $96(37)$ \\
\hline $35-39$ & $53(29)$ & $37(30)$ & $51(23)$ & $41(20)$ & $29(21)$ & $42(16)$ \\
\hline $40+$ & $16(9)$ & $12(10)$ & $23(10)$ & $4(2)$ & $3(2)$ & $8(3)$ \\
\hline \multicolumn{7}{|l|}{ Proxy interview } \\
\hline Yes & $15(8)$ & $8(7)$ & $26(12)$ & $2(1)$ & $1(1)$ & $3(1)$ \\
\hline No & $167(92)$ & $114(93)$ & $197(88)$ & 200 (99) & 139 (99) & $256(99)$ \\
\hline \multicolumn{7}{|c|}{ Smoked in year before index pregnancy $y^{a, b}$} \\
\hline Yes & $59(32)^{a}$ & $28(23)$ & $45(20)$ & $49(24)$ & $32(23)$ & $40(15)$ \\
\hline No & $123(68)$ & $94(77)$ & $178(80)$ & $153(76)$ & $108(77)$ & $220(85)$ \\
\hline \multicolumn{7}{|l|}{ Body mass index } \\
\hline$<25$ & $55(30)$ & $35(29)$ & $76(34)$ & $137(68)$ & $100(71)$ & $167(66)$ \\
\hline$\geq 25$ & $126(70)$ & $87(71)$ & $147(66)$ & $65(32)$ & 40 (29) & $87(34)$ \\
\hline \multicolumn{7}{|l|}{ Child's birth year ${ }^{\mathrm{d}}$} \\
\hline 1991-1997 & & & & $15(7)$ & $6(4)$ & $28(11)$ \\
\hline 1998 & & & & $25(12)$ & $18(13)$ & $19(7)$ \\
\hline 1999 & & & & $27(13)$ & $18(13)$ & $30(11)$ \\
\hline 2000 & & & & $29(14)$ & $21(15)$ & $43(16)$ \\
\hline 2001 & & & & $27(13)$ & $20(14)$ & $38(15)$ \\
\hline 2002 & & & & $23(11)$ & $14(10)$ & $29(11)$ \\
\hline 2003 & & & & $21(10)$ & $16(11)$ & $36(14)$ \\
\hline 2004-2006 & & & & $35(17)$ & 27 (19) & $37(14)$ \\
\hline
\end{tabular}

"Differences between fathers of all cases and fathers of controls were statistically significant for race/ethnicity $(P<0.001)$, educational level $(P<0.001)$, marital status $(P=0.02)$ and smoking $(P=0.006)$. The difference between fathers of cases in case-control sets and fathers of controls was statistically significant for educational level $(P=0.02)$.

'Differences between mothers of all cases and mothers of controls were statistically significant for race/ethnicity $(P=0.004)$, educational level $(P<0.001)$, marital status $(P<0.001)$ and smoking $(P=0.02)$. No differences between mothers of cases in case-control sets and mothers of controls were statistically significant.

'Income missing for 14 case fathers, 26 control fathers, 40 case mothers, and 32 control mothers

${ }^{\mathrm{d}}$ Child's birth year shown only for mothers.

TABLE 1. Demographic and Other Characteristics of Sporadic Bilateral Retinoblastoma Cases

\author{
and Controls
}




\begin{tabular}{|c|c|c|c|c|c|c|}
\hline \multirow[b]{2}{*}{ Food group } & \multicolumn{3}{|c|}{ Complete population } & \multicolumn{3}{|c|}{ Case-control sets } \\
\hline & $\begin{array}{l}\text { OR for increase of } \\
1 \text { serving/day }\end{array}$ & 95\% CI & $P$ & $\begin{array}{l}\text { OR for increase of } \\
1 \text { serving/day }\end{array}$ & $95 \% \mathrm{CI}$ & $P$ \\
\hline Fruit & 0.84 & $0.69,1.04$ & 0.10 & 0.73 & $0.54,0.99$ & 0.04 \\
\hline Dairy & 0.78 & $0.65,0.94$ & 0.01 & 0.73 & $0.57,0.92$ & 0.008 \\
\hline Vegetables & 1.08 & $0.89,1.30$ & 0.44 & 1.06 & $0.84,1.34$ & 0.61 \\
\hline Meat and seafood & 1.44 & $1.01,2.04$ & 0.04 & 1.59 & $1.05,2.41$ & 0.03 \\
\hline Fresh red meat & 0.80 & $0.48,1.33$ & 0.38 & 0.89 & $0.46,1.72$ & 0.73 \\
\hline Cured meat & 2.46 & $1.28,4.76$ & 0.007 & 4.94 & $2.06,11.80$ & $<0.001$ \\
\hline Poultry & 1.64 & $0.73,3.67$ & 0.23 & 1.02 & $0.37,2.80$ & 0.97 \\
\hline Seafood & 2.06 & $0.82,5.18$ & 0.08 & 1.94 & $0.63,5.95$ & 0.24 \\
\hline Grains & 1.04 & $0.82,1.32$ & 0.73 & 1.08 & $0.82,1.41$ & 0.59 \\
\hline Fats & 1.05 & $0.78,1.39$ & 0.76 & 1.16 & $0.84,1.60$ & 0.37 \\
\hline Sweets including beverages & 1.13 & $0.94,1.36$ & 0.19 & 1.27 & $1.02,1.57$ & 0.03 \\
\hline Fried food & 1.87 & $0.86,4.05$ & 0.11 & 1.61 & $0.61,4.23$ & 0.33 \\
\hline Alcohol & 1.09 & $0.80,1.49$ & 0.59 & 1.08 & $0.75,1.58$ & 0.67 \\
\hline
\end{tabular}

aAdjusted for father's race/ethnicity (non-Hispanic white, other), father's educational level (less than college graduate, college graduate), father's energy intake, child's birth year.

TABLE 2. Father's Intake of Food Groups in Relation to Child’s Risk of Sporadic Bilateral

Retinoblastoma

\begin{tabular}{|c|c|c|c|c|c|c|}
\hline \multirow[b]{2}{*}{ Food group } & \multicolumn{3}{|c|}{ Complete population } & \multicolumn{3}{|c|}{ Case-control sets } \\
\hline & $\begin{array}{l}\text { OR for increase of } \\
1 \text { serving/day }\end{array}$ & $95 \%$ CI & $P$ & $\begin{array}{l}\text { OR for increase of } \\
1 \text { serving/day }\end{array}$ & $95 \% \mathrm{CI}$ & $P$ \\
\hline Fruit & 0.90 & $0.74,1.09$ & 0.28 & 0.88 & $0.70,1.10$ & 0.26 \\
\hline Dairy & 0.95 & $0.81,1.11$ & 0.50 & 1.01 & $0.84,1.21$ & 0.90 \\
\hline Vegetables & 1.04 & $0.90,1.20$ & 0.60 & 1.07 & $0.90,1.27$ & 0.45 \\
\hline Meat and seafood & 1.03 & $0.72,1.47$ & 0.88 & 1.03 & $0.69,1.55$ & 0.87 \\
\hline Fresh red meat & 0.87 & $0.49,1.54$ & 0.63 & 1.02 & $0.50,2.07$ & 0.97 \\
\hline Cured meat & 1.23 & $0.64,2.35$ & 0.53 & 1.37 & $0.62,3.00$ & 0.44 \\
\hline Poultry & 1.10 & $0.53,2.30$ & 0.80 & 0.82 & $0.32,2.11$ & 0.69 \\
\hline Seafood & 0.98 & $0.38,2.53$ & 0.97 & 0.86 & $0.27,2.76$ & 0.81 \\
\hline Grains & 0.91 & $0.73,1.15$ & 0.44 & 0.99 & $0.76,1.28$ & 0.92 \\
\hline Fats & 0.98 & $0.75,1.27$ & 0.87 & 0.97 & $0.71,1.32$ & 0.84 \\
\hline Sweets including beverages & 1.17 & $0.98,1.41$ & 0.09 & 1.16 & $0.93,1.44$ & 0.19 \\
\hline Fried food & 1.48 & $0.75,2.93$ & 0.26 & 1.12 & $0.44,2.86$ & 0.82 \\
\hline Alcohol & 0.91 & $0.53,1.57$ & 0.74 & 0.86 & $0.44,1.69$ & 0.67 \\
\hline
\end{tabular}

"Adjusted for mother's race/ethnicity (non-Hispanic white, other), mother's educational level (less than college graduate, college graduate), mother's energy intake, child's birth year.

TABLE 3. Mother's Intake of Food Groups in Relation to Child's Risk of Sporadic Bilateral

Retinoblastoma 


\begin{tabular}{|c|c|c|c|c|c|c|c|c|c|c|c|c|}
\hline \multirow[b]{3}{*}{ Food group } & \multicolumn{6}{|c|}{ Complete population } & \multicolumn{6}{|c|}{ Matched sets } \\
\hline & \multicolumn{3}{|c|}{ Minimal model ${ }^{\mathrm{a}}$} & \multicolumn{3}{|c|}{ Full model $^{\mathrm{b}}$} & \multicolumn{3}{|c|}{ Minimal model ${ }^{\mathrm{a}}$} & \multicolumn{3}{|c|}{ Full model $^{\mathrm{c}}$} \\
\hline & OR & $95 \% \mathrm{CI}$ & $P$ & OR & $95 \%$ CI & $P$ & OR & $95 \% \mathrm{CI}$ & $P$ & OR & $95 \%$ CI & $P$ \\
\hline Fruit & 0.92 & $0.73,1.14$ & 0.44 & 0.82 & $0.63,1.06$ & 0.13 & 0.87 & $0.62,1.22$ & 0.43 & 0.69 & $0.43,1.11$ & 0.12 \\
\hline Dairy & 0.80 & $0.66,0.97$ & 0.03 & 0.79 & $0.64,0.97$ & 0.03 & 0.80 & $0.61,1.05$ & 0.11 & 0.70 & $0.49,1.00$ & 0.047 \\
\hline Cured meats & 2.18 & $1.11,4.28$ & 0.02 & 1.75 & $0.83,3.71$ & 0.14 & 4.64 & $1.89,11.44$ & $<0.001$ & 5.05 & $1.46,17.51$ & 0.01 \\
\hline Sweets & 1.07 & $0.87,1.30$ & 0.53 & 1.12 & $0.90,1.40$ & 0.30 & 1.27 & $0.98,1.65$ & 0.07 & 1.55 & $1.08,2.23$ & 0.02 \\
\hline
\end{tabular}

"Adjusted for the 3 other food groups, father's race/ethnicity (non-Hispanic white, other), father's educational level (less than college graduate, college graduate), father's energy intake, child's birth year.

bAdjusted for the 3 other food groups, father's multivitamin supplement use, father's vitamin C supplement use, father's calcium supplement use, mother's multivitamin supplement use, mother's cigarette smoking ( 3 levels) and mother's medical radiation dose ( 3 levels), in addition to the variables in the minimally adjusted model.

'Adjusted for father's multivitamin supplement use, father's vitamin C supplement use, father's calcium supplement use, father's medical radiation dose ( 3 levels), mother's multivitamin supplement use, mother's cigarette smoking ( 3 levels) and mother's medical radiation dose ( 3 levels), in addition to the variables in the minimally adjusted model.

TABLE 4. Simultaneous Analysis of Four Food Groups of Fathers in Relation to Child's Risk of Sporadic Bilateral Retinoblastoma 


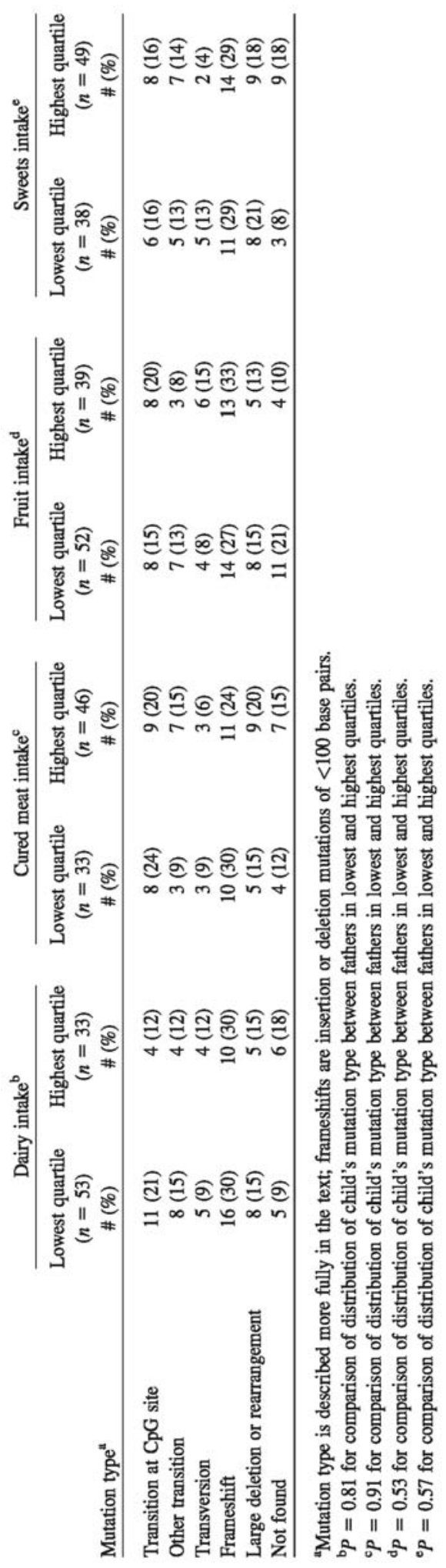

TABLE 5 RB1 Mutation Type by Father's Intake of Selected Food Groups 


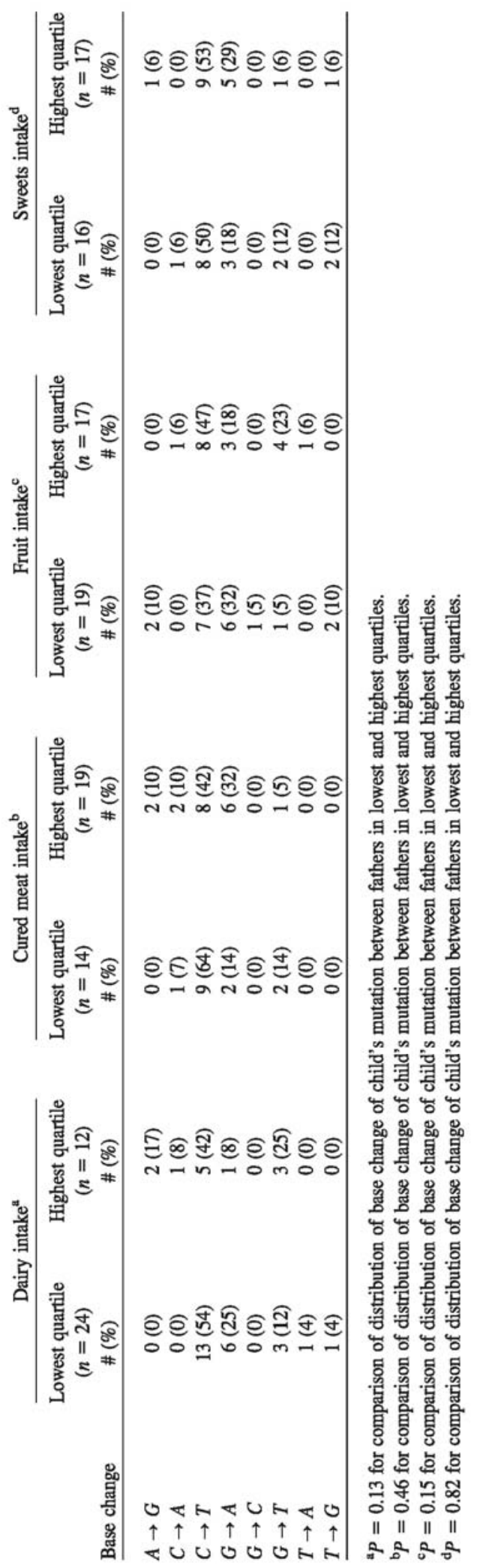

TABLE 6. Base Change in RB1 Mutation by Father's Intake of Selected Food Groups 